\title{
TESTE DE GERMINAÇÃO COM ACONDICIONAMENTO DOS ROLOS DE PAPEL EM SACOS PLÁSTICOS ${ }^{1}$
}

\author{
ROGÉRIO DEANDRADE COIMBRA², CAMILADEAQUINO TOMAZ ${ }^{3}$ CIBELE CHALITAMARTINS ${ }^{4}$, JOÃONAKAGAWA ${ }^{5}$
}

\begin{abstract}
RESUMO - O teste de germinação é realizado em laboratório, sob condições de ambiente controlado e favorável, visando a obtenção da mais completa e rápida germinação dos lotes de sementes. O substrato utilizado deve manter umidade suficiente para o processo de germinação, sendo que, muitas vezes os rolos de papel umedecidos necessitam ser acondicionados em sacos plásticos. O excesso de umidade também pode ser prejudicial à germinação, provocando atraso ou paralisação do desenvolvimento das plântulas. Essas alterações podem tornar o teste não representativo da verdadeira qualidade do lote. O objetivo do trabalho foi avaliar o efeito de embalagens plásticas, no acondicionamento dos conjuntos de rolo de papel mais sementes, durante o teste de germinação conduzido em germinadores de câmara vertical tipo B.O.D., visando a maximização dos resultados. Foram avaliadas duas espessuras $(0,033 \mathrm{~mm}$ e $0,050 \mathrm{~mm})$ e a presença ou a ausência de perfurações (128 furos de $5 \mathrm{~mm}$ de diâmetro por face de $60 \mathrm{~cm}$ x $40 \mathrm{~cm}$ ), nos sacos plásticos transparentes utilizados durante a realização do teste de germinação, para as seguintes espécies: milho doce (cv. 'Doce Cristal' e cv. 'Super Doce'), feijão (cv. 'Pérola' e cv. 'IAC-Carioca Tybatã') e soja (cv. 'Embrapa48' dois lotes). Para sementes de milho doce e feijão, os tratamentos plástico grosso ou fino perfurados e plástico fino inteiro promoveram os melhores resultados do teste de germinação. Concluiu-se que, a espessura do plástico e a presença ou ausência de perfurações são fatores que interferem nos resultados do teste de germinação conduzido em germinadores de câmara vertical tipo B.O.D.
\end{abstract}

Temos para indexação: sementes, substrato, umidade.

\section{GERMINATION TEST WITH PACKGAING THE ROLLS OF PAPER IN PLASTIC SACKS}

\begin{abstract}
The germination test is performed in the laboratory under controlled environment aiming for complete and fast germination of the seed lot. During the germination test the substrate used must be kept moist to allow seed germination. Thus, the paper roll used needs to be kept in plastic bags to preserve the moisture required for germination. Excess of moisture may also affect seed germination, cause delay or paralyzation of seedling development. These modifications may give results that are not reliable, which do not represent the real quality of the seed lot. Therefore, the objective of this study was to identify the conditions of packaging the paper rolls in plastic sacks to optimize the results of the germination test carried out in a vertical B.O.D. type chamber. Two thickness of transparent plastic bags $(0,033 \mathrm{~mm}$ and $0,050 \mathrm{~mm})$ were evaluated and the presence or absence of perforation ( 128 holes of $5 \mathrm{~mm}$ diameter $\mathrm{mm}$ per size of $60 \mathrm{~cm} \mathrm{x} 40 \mathrm{~cm}$ ). The following species were used: sweet corn (cv. 'Doce Cristal' and cv. 'Super Doce'), bean (cv. 'Pérola' and cv. 'IAC-Carioca Tybatã') and soybean (cv. 'Embrapa-48' two lots). For sweet corn and bean seeds, the treatments perforated thick plastic, whole fine plastic and perforated fine plastic promoted the
\end{abstract}

${ }^{1}$ Submetido em 28/04/2006. Aceito para publicação em 09/01/2007.

${ }^{2}$ Eng $^{\text {o. }}$ Agr ${ }^{\circ}$., pós-graduando do Depto. de Produção Vegetal-Agricultura, FCA/UNESP-Botucatu-SP. racoimbra@ fca.unesp.br.

${ }^{3}$ Aluna de graduação em agronomia, FCA/UNESP-Botucatu-SP. catomaz@fca.unesp.br.

\footnotetext{
${ }^{4}$ Eng $^{\text {a }}$.Agr ${ }^{\text {a. }}$, Dr., Professora voluntária, Depto. de Produção Vegetal - FCA - UNESP - Campus Botucatu, Caixa Postal 237, CEP. 18603-790 Botucatu - SP. secdamv@fca.unesp.br.

${ }^{5}$ Eng $^{\circ}$.Agr ${ }^{\circ}$., Dr., Professor Titular Aposentado - Voluntário, Depto. de Produção Vegetal - FCA - UNESP - Campus Botucatu, Caixa Postal 237, CEP. 18603-790 Botucatu - SP. secdamv@fca.unesp.br.
} 
best results in the germination test. These results led to the conclusion that the thickness of the plastic and the presence of perforations were factors that interfered in the results of the germination test carried out in vertical B.O.D. type chamber.

Index terms: seeds, substrate, moisture.

\section{INTRODUÇÃO}

Os resultados do teste de germinação são utilizados para comparar a qualidade fisiológica de lotes, determinar a taxa de semeadura e servir como parâmetro de comercialização de sementes. Para fins comerciais, a adoção de um procedimento padrão na instalação, condução e avaliação dos testes permite a obtenção de resultados comparáveis entre laboratórios de empresas fornecedoras e compradoras de sementes (Marcos Filho et al., 1987; ISTA, 2004). Assim, o teste é realizado seguindo-se uma metodologia padronizada, sob condições artificiais controladas de laboratório, altamen-te favoráveis, para que se obtenha a maior porcentagem de germinação no menor tempo possível.

A partir da década de 1970, houve a intensificação na realização de trabalhos voltados à padronização da quantidade de água no umedecimento do substrato para o teste de germinação, visto que os laboratórios de rotina utilizavam critérios próprios de umedecimento, que levavam a variações inaceitáveis entre os resultados dos testes (Peterson e Cooper, 1979; Phaneendranath, 1980; Eira e Barros, 1987; Tanaka et al., 1991; Menezes et al., 1993 e Novembre e Marcos Filho, 1999).

O substrato utilizado para a germinação deve, durante todo o período do teste, manter umidade suficiente para garantir que o processo de germinação ocorra de forma plena, pois a deficiência de água impossibilita a sequiência dos processos bioquímicos, físicos e fisiológicos, que determina a retomada do crescimento do embrião. Entretanto, a umidade não pode ser excessiva, pois pode limitar a aeração e prejudicar a germinação (Pollock, 1974; ISTA, 2004).

Durante a realização do teste de germinação, restrições de oxigênio podem provocar atraso ou paralisação no desenvolvimento das plântulas ou, ainda, a ocorrência de anormalidades, como a ausência de raízes e a formação de plântulas hialinas (Phaneendranath, 1980). Estas alterações relacionadas à metodologia adotada no teste provocam variações de resultados indesejáveis.

Embora seja preconizada, a adição subseqüente de água durante o teste de germinação deve ser evitada sempre que possível, pois pode provocar um aumento na variabilidade entre as repetições e entre os testes. $\mathrm{O}$ analista deve observar diariamente os substratos e adicionar água somente em casos extremos (Brasil, 1992; ISTA, 2004).

Dentre as sementes mais sensíveis ao excesso de água, destacam-se as leguminosas, soja (Tao, 1981), feijão e amendoim, além de algodão, sorgo e sementes pequenas de gramíneas forrageiras (Toledo e Pedreira, 1984) e de hortaliças (Gentil e Torres, 2001). Tentando minimizar o efeito do umedecimento inadequado do substrato no teste de germinação, as Regras para Análise de Sementes (Brasil, 1992) recomendam a adição de volumes de água de 2,0 a 2,5 e de 2,5 a 3,0 vezes o peso do substrato de papel para sementes de gramíneas e leguminosas, respectivamente.

Atualmente, a grande dificuldade de manutenção do teor de água do substrato durante o teste de germinação advém dos germinadores utilizados. Alguns, conhecidos também como B.O.D. (Biochemical Oxygen Demand), têm controle de temperatura e de fotoperíodo, mas não controlam a umidade relativa do ar. Embora exista um difusor de ar interno visando minimizar essas variações, muitas vezes, verificamse variações de temperatura no seu interior. Tais ocorrências provocam discrepâncias nos resultados das repetições de testes de germinação colocadas nestes germinadores e mesmo mantendo-se a casualização dos tratamentos ou lotes avaliados dentro do germinador, ainda assim, observa-se maior germinação em algumas prateleiras, de forma aleatória.

Com o intuito de evitar o ressecamento do substrato no interior dos germinadores, a ISTA (2004) recomenda a manutenção do conjunto do teste de germinação em embalagens, que devem possuir dimensão e espessura adequada às trocas gasosas com o ambiente do germinador, possibilitando assim a difusão do oxigênio para o seu interior, sem, contudo perder água. Entretanto, não há uma recomendação da espessura desse material e nem como o conjunto deve ser acondicionado dentro do mesmo. Assim, os materiais e métodos utilizados ainda não estão devidamente padronizados, o que pode causar dúvidas e dificultar a reprodução dos resultados do teste.

O objetivo do trabalho foi avaliar o efeito de embalagens plásticas, no acondicionamento dos conjuntos de rolo de papel mais sementes, durante o teste de germinação conduzido em germinadores de câmara vertical tipo B.O.D., visando a maximização dos resultados. 


\section{MATERIALE MÉTODOS}

O experimento foi conduzido no Laboratório de Análise de Sementes do Departamento de Produção Vegetal - Setor Agricultura, da Faculdade de Ciências Agronômicas, da Universidade Estadual Paulista (UNESP), em Botucatu - SP.

No teste de germinação foram utilizadas sementes das seguintes espécies: Milho (cultivares 'Doce Cristal' e 'Super doce'), Soja (dois lotes da cultivar 'Embrapa-48') e Feijão (cultivares 'Pérola' e 'IAC-Carioca Tybatã').

Os testes foram instalados com cinco repetições de 50 sementes por lote, em rolos de papel umedecidos com água deionizada, na proporção de 2,5 vezes o peso do papel seco, à temperatura de $25^{\circ} \mathrm{C}$. As contagens foram feitas aos $4 \mathrm{e} 7$ dias; aos 5 e 8 e aos 5 e 9, respectivamente, para o milhodoce, a soja e o feijão, contabilizando-se, na contagem final, a porcentagem de plântulas normais, anormais e sementes mortas (Brasil, 1992).

$\mathrm{Na}$ condução do teste de germinação, foram utilizados para envolver os conjuntos de rolos de papel com as sementes, sacos plásticos de polietileno transparente, nas dimensões de $40 \mathrm{~cm}$ x $60 \mathrm{~cm}$ com as espessuras de $0,033 \mathrm{~mm}$ (plástico fino) ou $0,050 \mathrm{~mm}$ (plástico grosso), perfurados (128 furos de $5 \mathrm{~mm}$ de diâmetro por face) ou não, constituindo assim quatro tratamentos denominados: plástico grosso inteiro; plástico grosso perfurados; plástico fino inteiro e plástico fino perfurados.

O germinador utilizado foi uma câmara vertical, tipo B.O.D., contendo 10 prateleiras removíveis de arame, controle de temperatura, circulador de ar, através de ventoinha contínua e difusor vertical, com água na cuba superior e inferior. Durante a realização do experimento, todas as prateleiras do germinador foram ocupadas pelos sacos plásticos dispostos na posição horizontal.
Cada saco plástico acondicionou 10 rolos de papel com sementes, sendo usado um saco plástico para cada espécie e para cada tratamento.

Antes da instalação do teste de germinação, o teor de água das sementes foi determinado pelo método da estufa a $105 \pm 3{ }^{\circ} \mathrm{C}$ por $24 \mathrm{~h}$ (Brasil, 1992), utilizando-se duas subamostras de 25 sementes para cada lote.

Para a determinação da perda de umidade do substrato, durante o teste de germinação pesou-se o conjunto saco plástico, substrato umedecido mais sementes na montagem do teste, na data da primeira contagem e após a contagem final, mantendo-se as plântulas normais, anormais e mortas, obtendo-se por diferença a porcentagem de água perdida.

O delineamento experimental empregado foi o inteiramente casualizado, com quatro tratamentos e cinco repetições para cada espécie. Os dados em porcentagem que apresentaram valores nulos foram transformados em $(x+$ $0,5)^{1 / 2}$, para a seguir, serem submetidos à análise estatística (Gomes, 2000; Barbin, 2003). Os demais dados foram analisados sem transformação. As médias foram comparadas pelo teste Tukey a 5\% de significância. As médias apresentadas nas tabelas são dos dados originais.

\section{RESULTADOS E DISCUSSÃO}

Os sacos plásticos sem perfurações, tanto o grosso quanto o fino, foram mais eficientes na manutenção da umidade do substrato durante todo o teste de germinação. Contrariamente, os sacos plásticos perfurados permitiram maior desidratação do substrato durante o teste, estando mais secos ao final do teste, do que na data da primeira contagem (Tabelas 1, 2 e 3).

O teor de água inicial das sementes de milho-doce era de 7,2\% para a cultivar Doce Cristal e de 7,8\% para a cultivar

TABELA 1. Resultados do teste de germinação de sementes de milho doce e perda de água do substrato devido à forma de acondicionamento dos rolos de papel. Botucatu, 2004.

\begin{tabular}{|c|c|c|c|c|c|c|c|c|c|c|}
\hline \multirow{3}{*}{ Tratamento } & \multicolumn{10}{|c|}{ Teste de Germinação } \\
\hline & \multicolumn{2}{|c|}{$\begin{array}{c}\text { Primeira Contagem } \\
(\%)\end{array}$} & \multicolumn{2}{|c|}{$\begin{array}{c}\text { Plântulas } \\
\text { Normais (\%) } \\
\end{array}$} & \multicolumn{2}{|c|}{$\begin{array}{c}\text { Plântulas } \\
\text { Anormais (\%) } \\
\end{array}$} & \multicolumn{2}{|c|}{$\begin{array}{l}\text { Sementes } \\
\text { Mortas (\%) }\end{array}$} & \multicolumn{2}{|c|}{$\begin{array}{l}\text { Perda de Água do } \\
\text { Substrato (\%) }\end{array}$} \\
\hline & $\begin{array}{l}\text { Doce } \\
\text { Cristal }\end{array}$ & $\begin{array}{l}\text { Super } \\
\text { Doce }\end{array}$ & $\begin{array}{l}\text { Doce } \\
\text { Cristal }\end{array}$ & $\begin{array}{l}\text { Super } \\
\text { Doce }\end{array}$ & $\begin{array}{l}\text { Doce } \\
\text { Cristal }\end{array}$ & $\begin{array}{l}\text { Super } \\
\text { Doce }\end{array}$ & $\begin{array}{l}\text { Doce } \\
\text { Cristal }\end{array}$ & $\begin{array}{l}\text { Super } \\
\text { Doce }\end{array}$ & $\begin{array}{c}1^{\mathrm{a}} \\
\text { Contagem }\end{array}$ & Final \\
\hline Plástico Grosso Inteiro & $0 \mathrm{~b}$ & $0 \mathrm{~b}$ & $29 \mathrm{~b}$ & $23 \mathrm{~b}$ & $59 \mathrm{a}$ & $67 \mathrm{a}$ & $12 \mathrm{a}$ & $10 \mathrm{a}$ & 0,8 & 2,1 \\
\hline Plástico Grosso Perfurado & lo18 a & $51 \mathrm{a}$ & $79 \mathrm{a}$ & $87 \mathrm{a}$ & $17 \mathrm{~b}$ & $10 \mathrm{~b}$ & $4 \mathrm{ab}$ & $3 \mathrm{a}$ & 8,3 & 21,5 \\
\hline Plástico Fino Inteiro & $29 \mathrm{a}$ & $45 \mathrm{a}$ & $86 \mathrm{a}$ & $83 \mathrm{a}$ & $11 \mathrm{~b}$ & $10 \mathrm{~b}$ & $3 \mathrm{ab}$ & $7 \mathrm{a}$ & 0,3 & 1,3 \\
\hline Plástico Fino Perfurado & $33 \mathrm{a}$ & $50 \mathrm{a}$ & $81 \mathrm{a}$ & $85 \mathrm{a}$ & $17 \mathrm{~b}$ & $12 \mathrm{~b}$ & $2 \mathrm{~b}$ & $3 \mathrm{a}$ & $7,2 * *$ & 19,9 \\
\hline C.V. $(\%)$ & 23,07 & 11,06 & 8,79 & 6,96 & 15,38 & 17,03 & 50,04 & 39,30 & & \\
\hline
\end{tabular}

Médias na coluna seguidas da mesma letra não diferem entre si significativamente a 5\% de probabilidade pelo teste Tukey. *Sem análise estatística. 

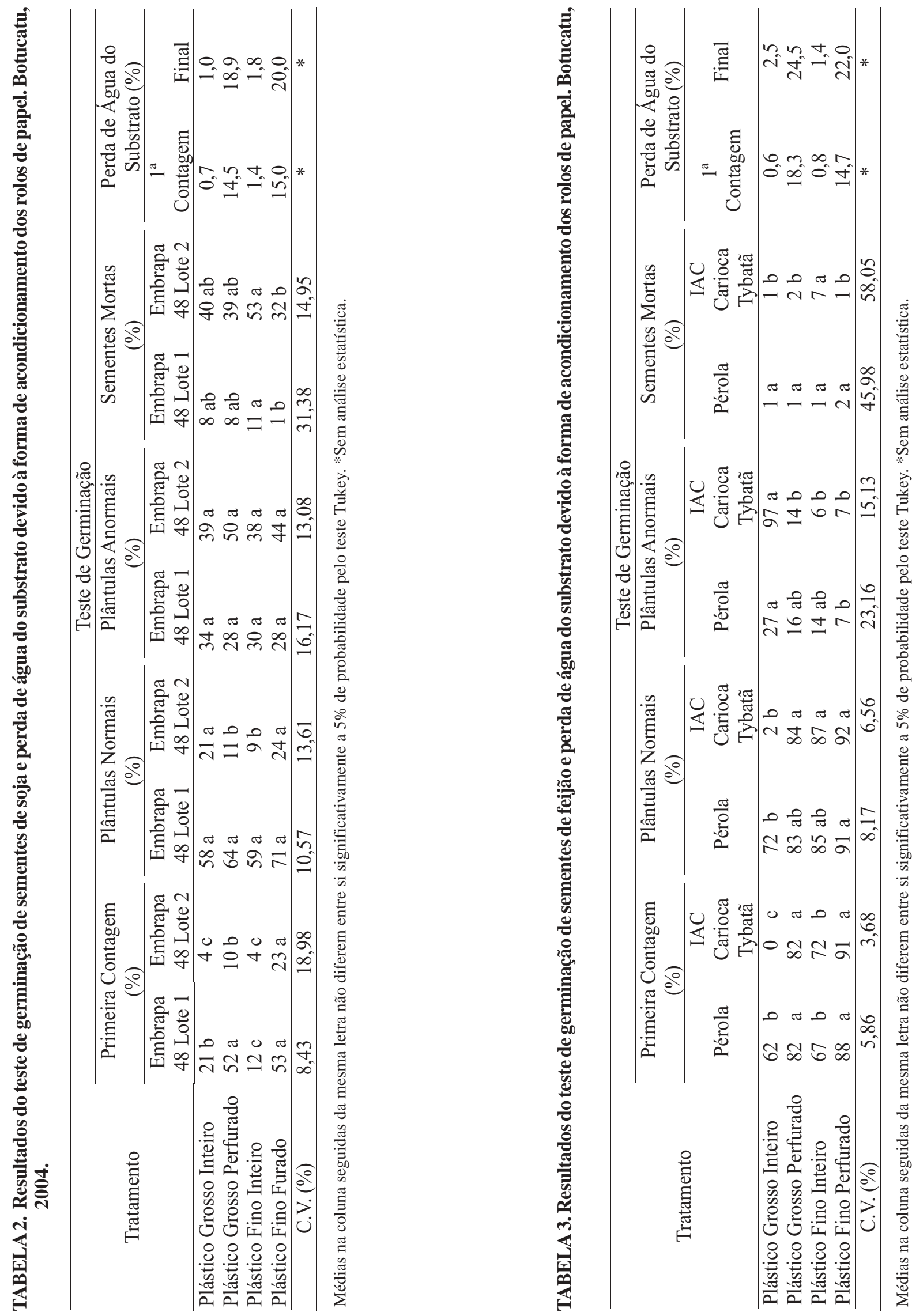
Super Doce, sendo pequena a variação entre as cultivares, o que leva a inferir que esta não deve ter afetado os resultados do teste.

Para ambas cultivares de milho, o acondicionamento dos rolos de papel em plástico grosso perfurado, plástico fino inteiro e plástico fino perfurado, proporcionou os maiores resultados de germinação (Tabela 1).

A utilização do plástico grosso inteiro prejudicou o processo de germinação, elevando significativamente a porcentagem de plântulas anormais. Isto, provavelmente, ocorreu devido à falta de aeração adequada durante o processo germinativo, ou seja, o plástico grosso sem furos embora promova uma boa manutenção da umidade do substrato, deve dificultar a difusão do oxigênio prejudicando assim o processo germinativo (Gorni, 2006). No caso do plástico fino inteiro, este também manteve a umidade do substrato, mas não impediu a difusão dos gases e, por isso, não prejudicou o processo de germinação (Tabela 1).

Para as sementes de soja, o teor de água antes da instalação dos testes era de $11,5 \%$ para o lote 1 e de $9,6 \%$ para o lote 2, apresentando variação entre os lotes (Tabela 2).

Através dos resultados do teste de germinação e da primeira contagem, observou-se uma diferença entre os lotes, sendo que o lote 1 foi considerado com maior qualidade do que o lote 2 (Tabela 2). Para o lote 1 , a porcentagem de plântulas normais não foi afetada pela forma de acondicionamento dos rolos, no entanto, o lote 2 apresentou redução na porcentagem de plântulas normais, no acondicionamento em plástico grosso perfurado e fino inteiro, por provável influência da menor qualidade das sementes, destacado pelo elevado número de plântulas anormais e sementes mortas (Tabela 2).

Para ambos lotes de soja, o teste da primeira contagem indica que o acondicionamento em sacos plásticos inteiros (sem furos), atrasa o processo de germinação, embora este problema seja atenuado com o decorrer do tempo, não afetando a porcentagem de plântulas normais ao final do teste no lote de maior qualidade (Tabela 2).

O teor de água inicial das sementes de feijão, por ocasião do teste de germinação, era de 7,8\% para a cultivar Pérola e de $9,3 \%$ para a cultivar IAC-Carioca Tybatã, apresentando variação entre as cultivares, embora esta não pareça ter afetado os resultados (Tabela 3).

Os resultados do teste da primeira contagem indicaram que o acondicionamento em sacos plásticos perfurados, em ambas espessuras, foi favorável ao processo de germinação (Tabela 3). Já o plástico grosso inteiro foi desfavorável, principalmente para cultivar de feijão IAC-Carioca Tybatã, quando comparada aos outros tratamentos (Tabela 3).

De modo semelhante à primeira contagem, o acondicionamento em saco plástico grosso inteiro, resultou em baixa germinação (plântulas normais) para a cultivar IACCarioca Tybatã, mesmo ao final do período, destacando-se a significativa porcentagem de plântulas anormais (Tabela 3). Isto, provavelmente ocorreu pelo fato do plástico grosso impedir a difusão de vapores de água e oxigênio (Gorni, 2006) no decorrer do teste, prejudicando assim o processo germinativo, como conseqüência da alteração da via respiratória aeróbica para a fermentativa ou anaeróbica (Custódio et al., 2002).

Pela porcentagem de plântulas normais, pode-se observar que o acondicionamento em plástico grosso perfurado, plástico fino inteiro e perfurado foi favorável ao processo de germinação (Tabela 3).

As variações na germinação das sementes não estão relacionadas somente com problemas de temperatura e circulação de ar no interior dos germinadores, mas também com a capacidade de trocas de vapor d'água e ar (principalmente $\mathrm{O}_{2}$ ) para o interior dos sacos plásticos que envolvem os rolos de papel contendo as sementes no teste de germinação, como verificado para as três espécies aqui estudadas, influenciando dessa forma na disponibilidade de oxigênio para as sementes.

Sendo assim, os resultados obtidos para sementes de milho-doce e feijão, permitiram observar que, os tratamentos relativos ao plástico grosso perfurado, plástico fino inteiro e plástico fino perfurado promoveram os melhores resultados do teste de germinação. Para sementes soja, o mesmo não pode ser afirmado, por provável influência da menor qualidade das sementes testadas.

\section{CONCLUSÃO}

A espessura do plástico e a presença ou ausência de perfurações são fatores que interferem nos resultados do teste de germinação conduzido em germinadores de câmara vertical tipo B.O.D..

\section{REFERÊNCIAS}

BARBIN, D. Planejamento e análise de experimentos agronômicos. Arapongas: Midas, 2003. 208p.

BRASIL, Ministério da Agricultura e da Reforma Agrária. Regras para análise de sementes. Brasília: SNDA/DNDV/CLAV, 1992. $365 \mathrm{p}$. 
CUSTÓDIO, C.C.; MACHADO-NETO, N.B.; ITO, H.M.; VIVIAN, MR. Efeito da submersão em água de sementes de feijão na germinação e no vigor. Revista Brasileira de Sementes, Londrina, v.24, n.2, p.49-54, 2002.

EIRA, M.T.S.; BARROS, A.S.R. Influência da quantidade de água no substrato sobre a germinação de sementes de pepino (Cucumis sativus L.). In: CONGRESSO BRASILEIRO DE SEMENTES, 5., 1987, Gramado. Resumos. Brasília: ABRATES, 1987. p.60.

GENTIL, D.O.; TORRES, S.B. Umedecimento do substrato e germinação de sementes de maxixe (Cucumis anguria L.). Revista Brasileira de Sementes, Curitiba, v.23, n.2, p.113-116, 2001.

GOMES, F.P. Curso de estatística experimental. 14 ed. Piracicaba: ESALQ, 2000. 477 p.

GORNI, A.A. Introdução aos plásticos. Disponível em: < http:// www.gorni.eng.br/intropol.html>. Acesso em 06 abr. 2006.

INTERNATIONAL SEED TESTING ASSOCIATION. Germination. In: ISTA. International Rules for Seed Testing. Bassersdorf: ISTA, 2004. p.5.1- 5.5; 5A.1- 5A.50.

MARCOS FILHO, J.; CICERO, S.M.; SILVA, W.R. Avaliação da qualidade de sementes. Piracicaba: FEALQ, 1987.230 p.

MENEZES, N.L.; SILVEIRA, T.L.D.; STORCK, L. Efeito do nível de umedecimento do substrato sobre a germinação de cucurbitáceas. Ciência Rural, Santa Maria, v.23, n.2, p.157-160, 1993.
NOVEMBRE, A.D.L.C.; MARCOS FILHO, J. Estudo da metodologia para condução do teste de germinação em sementes de algodão deslintadas mecanicamente. Revista Brasileira de Sementes, Curitiba, v.21, n.2, p.187-193, 1999.

PETERSON, J.R.; COOPER, P.G. Some considerations of water in the germination test. Seed Science and Technology, Zürich, v.7, n.3, p.329-340, 1979.

PHANEENDRANATH, B.R. Influence of amount of water in the paper towel on standard germination tests. Journal of Seed Technology, Lansing, v.5, n.2, p.82-87, 1980.

POLLOCK, B.M. Effect of environment after sowing on viability. In: ROBERTS, E.H. (Ed.) Viability of seeds. London: Chapman and Hall, 1974. p.150-171.

TANAKA, M.A.S.; MARIANO, M.I.A.; LEÃO, N.V.M. Influência da quantidade de água no substrato sobre a germinação de sementes de amendoim. Revista Brasileira de Sementes, Brasília, v.13, n.1, p.73-76, 1991.

TAO, K.J. Physiological rupture of soybean hypocotyls in germination and vigor tests. Journal of Seed Technology, Boise, v.6, n.3, p.1-8, 1981.

TOLEDO, F.F.; PEDREIRA, A.A.S. Quantidade de solução de nitrato de potássio e germinação de sementes de capim colonião. Revista Brasileira de Sementes, Curitiba, v.6, n.1, p.61-70, 1984. 